\title{
"Transição política" e ditadura no Brasil: os anos 1970 e seus agendamentos políticos e intelectuais
}

\author{
"Political Transition" and Dictatorship in Brazil: \\ The 1970's and Their Political and Intellectual Agendas
}

Wanderson da Silva Chaves *

Júlio Barnez Pignata Cattai ${ }^{* *}$

\section{Resumo}

O artigo é prospectivo e encerra uma proposta de agenda de pesquisa. Apoia-se em recentes descobertas historiográficas e na pesquisa material dos autores e investiga o estabelecimento de uma tendência dos anos 1970: a da imaginação de projetos de prospecção da democracia, a partir da ditadura, por meio de agendas de "transição política". O foco da análise é duplo, mas relacionado: por um lado, apontamos formas como tais projetos foram agenciados, a partir de saberes e práticas intelectuais, entre temáticas como direitos humanos, questão social e Estado de Direito; de outro, sinalizamos a renovação, na década de 1970, das estratégias norte-americanas de Guerra Fria, fornecedora de vetores de agendamento e institucionalização, decisivos na constituição de modelos de "transição democrática".

Palavras-chave: ditadura; intelectuais; Guerra Fria; Brasil; ciências sociais.

\section{Abstract}

This essay is based on recent historiographical discoveries and on the material research of the authors and investigates the establishment of a tendency of the 1970s: that of the imagination of projects of prospecting of democracy from the dictatorship through 'political transition' agendas. The focus of the analysis is twofold but related: on the one hand, we deal with the intervention of knowledge and intellectual practices of such projects between themes such as human rights, social issues and the rule of law; on the other hand, we discuss the renewal in the 1970s of the US Cold War strategies, which provide the vectors of scheduling and institutionalization, decisive in the constitution of 'democratic transition' models.

Keywords: dictatorship; intellectuals; Cold War; Brazil; social sciences.

\footnotetext{
* Universidade de São Paulo (USP), Faculdade de Filosofia, Letras e Ciências Humanas (FFLCH), São Paulo, SP, Brasil. Doutor em História Social. wanderson_schaves@yahoo.com.br <http://orcid. org/0000-0001-9849-6750>

** Universidade de São Paulo (USP), Faculdade de Filosofia, Letras e Ciências Humanas (FFLCH), São Paulo, SP, Brasil. Doutor em História Social. juliocattai@gmail.com <http://orcid.org/0000-0002-8297-3345>
} 
Na década de 1970 foram sendo revisados, de maneiras ainda pouco compreendidas pela historiografia, os fundamentos das pretensões "antiautoritárias" das frentes "anticomunista" e "antitotalitária", particularmente os que indicavam como continuar a promover tais pretensões mediante agendas da "democratização", da "modernização" e do "desenvolvimento". Os proponentes dessa tríplice agenda diversificaram suas posições nos anos 1970, mas teriam permanecido, na busca que realizaram por novas áreas e objetos de intervenção, três premissas de trabalho já características desse campo político, comuns desde o pós-Segunda Guerra Mundial e que vinham fundamentadas na luta "anticomunista" e "antitotalitária": o combate a propostas orientadas a realizar mudanças por meio da "ruptura" dos sistemas políticos; o trabalho de criação institucional e de proteção de "valores" e, preliminar a esta segunda premissa, a formação de elites políticas, técnicas e intelectuais.

A hipótese trabalhada neste artigo é de que as propostas de "transição política", que pulularam durante e após os anos 1970 como solução às ditaduras, teriam trazido consigo um esforço de renovação desse tipo de estratégia de Guerra Fria, relançando, como novas propostas de ordem, dois legados desse pós-Segunda Guerra Mundial: a proposição da modernização por meio do "desenvolvimento", como enfrentamento evolutivo, gradual e seguro do "atraso" das sociedades; e a "guerra cultural" norte-americana, sustentada, na "promoção" e "proteção" da democracia, como instrumento de afirmação moral e ideológica de novos padrões de ordem internacional. ${ }^{1}$

Este trabalho pressupõe que a compreensão dessas propostas sobre a "transição democrática" passa, amiúde, pela investigação e desconstrução de saberes e práticas intelectuais que as formaram, bem como, portanto, dos vetores de agendamento e de institucionalização de seu debate. Compartilhamos do diagnóstico (Cancelli, 2017, Considerações Finais) de que há um esgotamento heurístico e de pesquisa material, na historiografia, dos relatos testemunhais e individuais de dor e denúncia contra o terror de Estado da ditadura (1964-1985); arriscam-se, com isso, as oportunidades em fazer justiça aos crimes e à violência de que são testemunhas. Em relação a essa tendência, de um enclausuramento da História em relatos de injustiças e sobre o seu "ressentimento", propomos uma ênfase alternativa: no autoritarismo - o terror -, na dimensão de seu estabelecimento institucional e estatal, em sua legitimação em objetivos intelectuais de "transição à democracia", cujos pressupostos, decisivamente, alcançam ainda hoje as formas de nossa vida pública. 
“Transição política” e ditadura no Brasil: os anos 1970 e seus agendamentos políticos e intelectuais

\section{TeOrias de Democratização e a Formulação DE AGENDAS DE TRANSIÇÃO NO BRASIL}

O cientista político Nicolas Guilhot, autor do fundamental The Democracy Makers (Guilhot, 2005), sustentou que as “teorias da democratização" ganharam importância com a retração abrupta dos projetos de revolução dos anos 1960; tornaram-se, progressivamente, portanto, as suas principais substitutas. $\mathrm{Na}$ adesão a essas teorias - na qual convergiram de conservadores e liberais a radicais de esquerda - observou-se, segundo o autor, um fenômeno central: a assimilação dos direitos humanos ao discurso de defesa da democracia. Essa assimilação, contudo, trouxera consigo modificações. Os direitos humanos foram sendo transformados, frente a um ideal tradicional de crítica do poder, em fundações do próprio poder, alterando-se, amplamente, as fontes buscadas da pretendida legitimidade de leis, do Direito, do Estado, de noções de soberania nacional e dos princípios de ordem internacional.

As "teorias da democratização", em que pese sua variedade de formulações, nas quais se inclui a incorporação dos direitos humanos, dariam continuidade, para o cientista político, a certas premissas do pós-Segunda Guerra Mundial sobre como buscar a mudança das sociedades. Assim, para Guilhot (2005, Introduction; Conclusion), a permanência pode ser encontrada na formação e na autonomia das elites; no fortalecimento de instituições e de seu princípio de autoridade, e em reformas orientadas à segurança e à estabilidade política.

No Brasil, desde os anos 1970, esse conjunto de premissas vinha sendo acolhido na política institucional e na vida intelectual do país por meio de um debate nacional sobre a retomada do Estado de Direito, a recomposição dos chamados direitos individuais e a retomada da "questão social", que, como já se encontra bastante estabelecido na literatura (Green, 2009), se faziam com fortes incentivos internacionais. Estabeleceu-se, no país, na forma de incentivos para a formação de uma agenda de trabalho intelectual, no qual pautaram-se um crescente interesse por uma nova governança, moralidade pública e formas de exercício do poder, e um renovado debate sobre que papéis a modernidade capitalista poderia exercer no enraizamento de uma ordem democrática no Brasil.

Uma dessas fontes de incentivo internacional era a Fundação Ford (Amorim, 2018), cuja política de fomento estruturou-se a partir de uma postulação tradicional da Sociologia e da Ciência Política norte-americanas dos anos 1950 e 1960. Em tal política observa-se a afirmação - fundamental para 
liberais e conservadores nos Estados Unidos e central na formulação de propostas de "intervenção ideológica", da Agência Central de Inteligência (CIA) e da diplomacia do Departamento de Estado - de que o compromisso dos intelectuais seria decisivo para as chances de vitória em uma "guerra psicológica" como a Guerra Fria (Chaves, 2018).

Nessa postulação, proveniente, sobretudo, da teoria sociológica das organizações, avaliava-se que o papel especializado dos intelectuais, ainda mais em sociedades "em formação" ("subdesenvolvidas", como o Brasil), era o de criação e de consolidação das instituições de uma determinada comunidade político-moral. ${ }^{2}$ Uma vez alienados de suas condições próprias de trabalho (ligadas à autonomia grupal e a uma colocação entre segmentos de elite) ou se afastados do coração da frente "antitotalitária" e "democrática", os intelectuais passariam, facilmente, de uma posição desejada de artífices da comunidade político-moral, de seu aprimoramento e de sua "institucionalização", à "subversão" e à "destruição da ordem". ${ }^{3}$ Tratava-se, nessa reflexão, portanto, da defesa de que a vida democrática evoluiria do estímulo e da orientação do ativismo de elites intelectuais, as quais, por sua vez, alicerçariam a criação de instituições, realizando a tarefa de proteger, em cada sociedade, os valores fundamentais à sua continuidade.

Na política de fomento da Fundação Ford essa postulação implicava a realização de duas exigências fundamentais como critérios de sucesso e desempenho: a capacidade de plena "institucionalização" e o poder de inspirar e incutir valores. Partia daí, por exemplo, a avaliação que fizera Peter S. Cleaves, cientista político integrante da equipe de seis assessores de programas da Fundação Ford do escritório de Lima, no Peru, da performance de certos beneficiários brasileiros, como o Instituto Universitário de Pesquisas do Rio de Janeiro (Iuperj). Em memorando de 1976, ${ }^{4}$ dirigido a Eduardo L. Venezian, chileno diretor (1974-1976) do escritório da Fundação no Brasil, Cleaves diagnosticava o Iuperj, entre outras jovens organizações apoiadas pela Fundação na América do Sul, como o Centro Brasileiro de Análise e Planejamento (Cebrap), de São Paulo, o Instituto de Estudios Peruanos, de Lima, e o Centro de Estudios de Estado y Sociedad (Cedes), de Buenos Aires, ${ }^{5}$ como parceiro decisivo que ainda não alcançara os parâmetros exigidos de habilitação plena como "instituição".

A avaliação de Cleaves baseava-se nas teses de Philip Selznick, sociólogo teórico das organizações, referenciado, textualmente, nessa avaliação do cientista político. Selznick, de fato, entendia por "habilitação" institucional principalmente o cumprimento de três requisitos: a definição de uma identidade 
coesa de grupo, afirmada em torno de "valores"; a encarnação dessa identidade na forma organizacional, em uma estrutura permanente; e a capacidade, de estrutura e de liderança da instituição, de gerar estratégias de reacomodação, representação e unidade diante de conflitos e de transformações internas (Selznick, 1957).

O teor da apreciação do Iuperj feita por Cleaves estendeu-se pelos anos 1970, sendo expressa em cada nova rodada de avaliação promovida pela Fundação Ford nessa década. Podemos encontrá-la, também, na análise de certos assessores de programas, como na do advogado James Gardner (de 1972), na do historiador e crítico literário Richard Morse (de 1975) e na do antropólogo Shepard Forman (de 1979). Nos memorandos que continham os pareceres desses assessores, ${ }^{6}$ Cândido Mendes de Almeida, o fundador e dirigente do Iuperj, aparece, assim, não sem motivo, como objeto central das análises. Por um lado, elogiosamente: sua atuação como intelectual público era reputada como impactante. Para Morse, em especial, Mendes era uma espécie de "príncipe da distensão" da ditadura, pois simbolizaria o sentido correto da "transição" e do papel dos intelectuais nessa fase. Por outro lado, Mendes seria caracteristicamente "autocrático" e "personalista", atributos que prejudicariam, para os pareceristas, a constituição dos requisitos executivos e culturais de "institucionalização" do Instituto.

Mas essa avaliação, quanto ao desempenho e ao papel desejáveis de uma liderança institucional, não se restringia a esses assessores de programas da Fundação Ford. Ela era parte de esforços mais amplos, conforme proposto por Guilhot (2005), de “teorias de democratização" do pós-Segunda Guerra Mundial, cuja perspectiva, sobre a importância das instituições para a consolidação democrática, se aproximava à defesa que fizera, desse ponto, um dos mais prestigiosos cientistas políticos norte-americanos de seu tempo, Samuel Huntington. À época, Huntington estava entre os responsáveis, na condição de consultor externo, por também avaliar o Iuperj para a Fundação. ${ }^{7}$ Esse pensador vinha, desde os anos 1950, sistematizando uma crítica conservadora a um "consenso liberal" do pós-Segunda Guerra Mundial: a defesa da conquista da democracia política como resultado da modernização econômica. ${ }^{8}$ Para pensadores como Huntington, períodos marcados por aceleradas transformações - como as ocorridas desde o fim da Segunda Guerra Mundial na economia de países como o Brasil $^{9}$ - trariam um potencial dissolvente para os sistemas políticos.

Segundo Samuel Huntington, apenas em circunstâncias de estabilidade a vida política de uma sociedade poderia assentar as bases de sua legitimidade. 
Para ele, essa legitimidade era conquistada por meio da capacidade de governo de maturar - se necessário, no longo prazo, e com recurso a mecanismos de promoção de participação ou de desmobilização social - a agregação e o reposicionamento de velhas e novas forças políticas. Para o cientista político, uma sociedade madura seria altamente "institucionalizada", condição alcançada quando ela se torna capaz de reformar-se a si mesma, modificando a composição do seu sistema político de maneira a fazer as mudanças serem sempre uma contribuição à estabilidade e à segurança de seus princípios de existência mais profundos. Ou seja, suas tradições (Cancelli, 2017, cap. 4).

No influente Political Order in Changing Societies (1968), Samuel Huntington sustentou que as "sociedades em modernização" deveriam elaborar, nesse amadurecimento de sua vida política, estratégias de promoção da "abertura" à participação política e concomitantemente o "fortalecimento" da ordem institucional. Sua sugestão a essas sociedades, para o ano de 1968, era de que trabalhassem uma proposta de modernização do mundo rural, integrando-o e diminuindo-lhe a importância na política e economia dos países, e, ao mesmo tempo, estratégias de arregimentação dos setores urbanos para a desmobilização da intelligentsia, a jovem e universitária especialmente. ${ }^{10}$ Para Huntington, esses dois focos de atuação constituiriam a melhor maneira de essas sociedades orientarem as demandas por participação política no sentido dos imperativos de "institucionalização".

O método de ação proposto por Huntington, baseado em escalonamento de grupos de poder e em agendamento das liberdades, segundo ele próprio, contribuiria até mesmo para uma diminuição do aspecto repressivo da vida política (como o da ditadura brasileira, de cujo núcleo político o cientista político, via Candido Mendes, esteve próximo na posição de consultor). ${ }^{11}$ Huntington indicava que a sobrevivência de regimes, governos e sociedades requeria a capacidade de se associarem às suas tradições, forças marginais ou recalcitrantes, transformando ou impondo, às fontes de instabilidade da mobilização cidadã ou da pressão popular, a forma e a expressão de procedimentos já estabelecidos; a chamada "institucionalização": o assentamento, no tecido social, de valores que conferem unidade moral à conservação de uma comunidade política (Huntington, 1968). ${ }^{12}$

A posição de Samuel Huntington com relação ao "desenvolvimentismo" era de suporte, mas com ressalvas, afastando-se, portanto, mas não de todo, da proposição geral dos liberais de centro dos Estados Unidos e que estava na base das políticas de fomento da Fundação Ford. Para o cientista político, o desenvolvimento poderia ser entendido como uma aposta no potencial de 
mudança das sociedades, de modo que as levasse a um estágio superior da modernidade, mas desde que mediante reformas que seguissem, estritamente, a lógica de organização, de cultura e de civilização dessas próprias sociedades. Huntington, como dissemos, questionava o potencial democrático das propostas desenvolvimentistas, apontando as chances de mudanças sociais destruírem realizações ou pretensões modernizantes, ao afetarem, diretamente, as condições da estabilidade política.

Huntington, aliás, em sua forte disposição para o cultivo das tradições como valor moral - e princípio de segurança -, duvidava que a democracia pudesse enraizar-se plenamente ou fazer-se presente com o "desenvolvimento" fora de seu "berço" europeu e norte-americano, chegando a questionar se seriam desejáveis para as relações externas dos Estados Unidos e para a ordem internacional. Huntington, um dos líderes do "neorrealismo" diplomático e da emergente orientação "neoconservadora", foi influente na concepção do chamado "paradigma da ordem política", proposta que, desde os anos 1970, vem influenciando o partido Democrata e dominando o partido Republicano (Ehrman, 1993). Amiúde colocavam-se para a política dos Estados Unidos, com esse paradigma, metas de combate à instabilidade por meio de um controle de expectativas sociais (e do próprio sentido de modernização) e pelo incentivo ao fortalecimento de sólidas alianças interclasses nos países, para o amparo à legitimidade de regimes e de governos, redundando, daí, uma política com forte viés de "institucionalização” (Mello, 2009).

\section{A CRISE DO “CONSENSO LIBERAL” E O AJUSTE “INSTITUCIONAL” DA DITADURA BRASILEIRA}

Desde o fim dos anos 1960, a posição liberal acerca do ideal normativo do "desenvolvimento" vinha sendo balançada, como a projeção de Huntington o demonstra, no coração de sua tese de sustentação. Atacava-se, nos seus parâmetros de "transição democrática" e de "institucionalização" estabelecidos na estratégia de Guerra Fria dos Estados Unidos, dos anos 1950 e 1960, a continuidade da postulação, feita particularmente a partir das "teorias de modernização" da sociologia norte-americana, de que a realização de um programa de desenvolvimento industrial, mediante "modernos saberes" das ciências econômicas e administrativas e da criação de novas estruturas e mecanismos jurídicos de intervenção estatal, teriam como consequência ulterior a organização de regimes democráticos (Gilman, 2003; Cattai, 2018). 
O apoio a essa postulação foi desafiado no âmbito doméstico, por exemplo, na atuação do Movimento dos Direitos Civis e, depois, do Poder Negro, ao tornarem explícito o fracasso da Great Society, ambicioso programa da administração Lyndon Johnson (1963-1969) de combate à pobreza e de superação da questão racial por meio do desenvolvimento econômico. Externamente, os protestos contra a Guerra do Vietnã e ao suporte a regimes ditatoriais cumpriram função semelhante: expunham o fracasso das promessas da tecnocracia desenvolvimentista e das teorias de modernização, também questionadas como princípio de relações internacionais por muitas das nações do "Terceiro Mundo" em fóruns multilaterais, como o da Organização das Nações Unidas (ONU). Essa série de acontecimentos, em conjunto, vinha desestabilizando a confiança no atribuído parâmetro ético do ativismo internacional norte-americano e do "desenvolvimentismo", isto é, o de ser uma resposta aos anseios de melhoramento humano e de justiça das sociedades descolonizadas e "subdesenvolvidas", repercutindo, por suposto, sobretudo, em prejuízo da capacidade de liderança moral dos Estados Unidos (Dezalay; Garth, 2002; Guilhot, 2011).

Conforme a visão panorâmica e abertamente visionária do cientista político Zbigniew Brzezinski, estrategista de política externa de Jimmy Carter (1977-1981), o establishment político norte-americano, dentro ou fora dos partidos Democrata e Republicano, avaliava que esses acontecimentos dos anos 1960 assinalavam a ocorrência de uma verdadeira "crise" no potencial de governo dos países, não apenas dos Estados Unidos. Ele frisara, em 1970 e, depois, na importante Comissão Trilateral, ${ }^{13}$ que presidia, o risco latente de propostas de "ruptura da ordem" minarem o sentido de autoridade dos governos, a coesão e o próprio sentido de continuidade das sociedades. Todavia, o elemento primordial da deflagração de conflitos sociais não se daria, segundo o cientista político, em razão de certo estado de miséria das populações, como pressupusera, nas décadas iniciais do pós-Segunda Guerra Mundial, o liberalismo norte-americano. Para Brzezinski, a "crise" era das "instituições", pelo esgotamento de papéis tradicionais desempenhados, por exemplo, por Igreja, Escola, Exército, bem como pelos poderes de Estado e por toda sua representação democrática (Brzezinski, 1971). As implicações seriam múltiplas e, no que diz respeito à política externa norte-americana, colocariam a questão de que o descrédito em relação às orientações de desenvolvimento econômico e do regime internacional de trocas comerciais, nos quais os seus programas de ajuda internacional estavam assentados, deveria motivar uma mudança de estratégias (Pereira, 2009). 
No Brasil, a "compressão" política, executada pela ditadura tendo em vista "institucionalizar" certos pilares de ordem e de segurança, passava a ser avaliada como necessitando de ajustes que permitissem, como salvaguardas à estabilidade e à continuidade do regime, uma assimilação progressiva e criteriosa de grupos sub-representados, novos ou que já houvessem desfrutado de acesso ao poder de Estado. Essa pretensão, que inaugurou, para o Brasil dos anos 1970, uma preocupação que mobilizaria toda uma intelectualidade internacional, partia de certas premissas.

A primeira partia do reconhecimento de que a "Revolução de 1964" estabeleceu relações mais apropriadas entre indivíduo e Estado, dando sustentação à modernização capitalista engendrada pela ditadura, que modificara a matriz de desenvolvimento do país. Seria a atualização de um esforço, que nos anos 1930 coubera a Getúlio Vargas, de tomar para o regime e para o Estado, contra certa exacerbação "individualista" do liberalismo, a missão de estabelecer e realizar os ideais do que deveria ser o "bem comum". A segunda postulava que um novo "amálgama" social, alicerce de uma futura ordem moderada e de centro, poderia ser produzido sem rupturas, pelo restabelecimento do Estado de Direito. Para tanto, uma nova "institucionalidade" deveria anteceder a esse restabelecimento, o que se daria por meio da modificação da estrutura de Estado e pelo cuidadoso direcionamento e sentido das liberdades e das possibilidades de organização e de participação civil. Abria-se uma temporada na qual passava-se a buscar, no trabalho intelectual, por exemplo, a reflexão sobre como poderiam ser essas novas possibilidades de engajamento público e de equilíbrio político (Cattai, 2018, cap. 5).

Importante notar que grupos liberais ainda sustentariam, em importantes organizações de seu ativismo, como na Fundação Ford, sua antiga convicção, abalada pela crítica de conservadores como Samuel Huntington, de que a democracia deveria ser uma possibilidade de realização universal, mediante atualização à modernidade econômica capitalista e à sua civilização de bem-estar (Chaves, 2018, Introdução; Korey, 2007).

É importante considerar que a proposição da renovação das alianças de poder no Brasil, em sua "natural" orientação para a estabilidade e para a segurança, ligava-se a toda uma nova disposição política e intelectual que historiadores como Inderjeet Parmar (2012, cap. 7 e 8) vão associar à emergência, a partir dos anos 1970, de uma nova teoria da "paz democrática". Segundo ele, a nova globalização econômica do período trouxe consigo propostas para uma nova arquitetura institucional mundial, inclusive para a constituição de suas novas bases sociais, no interior de uma sociedade civil renovada para esses fins. 
A teoria da paz democrática representava um desafio aos pressupostos huntingtonianos, da teoria realista de relações internacionais, tendo em vista a afirmação de que democracias poderiam ser constituídas tendo ou não os pré-requisitos materiais e sociais ideais. A tese, com desdobramentos na estratégia diplomática de países com atuação e objetivos globais, como os Estados Unidos, era de que países democráticos tenderiam, para sua própria proteção, para o estímulo de um ambiente democrático internacional, o que demandaria uma articulação intelectual, política e técnica desse tipo dedicada à expansão desse ambiente. Ou seja, de uma expansão da segurança interna e internacional apoiada em democracias.

Entretanto - esta é uma demonstração que nos importa neste trabalho -, havia convergência com os conservadores em certos entendimentos sobre como agir na promoção das chamadas "transições”. Em primeiro lugar, identificavam-se no combate das propostas "utópicas": viam no rompimento e fundação de novos sistemas políticos embriões de "totalitarismos" ou de "autoritarismos", pois, para eles, uma completa reversão da ordem e de seus valores representaria ameaça real de destruição do próprio Homem, pretendido por essas propostas. Em segundo, viam na "coesão social” o princípio da ordem democrática. Para eles, essa coesão era necessária para que houvesse segurança; posteriormente, menos recurso à coerção para o exercício do poder e, finalmente, $\mathrm{o}$ acesso às liberdades. Em terceiro lugar, entendiam que a construção de uma democracia sólida exigia a formação e recrutamento de elites. Estas deveriam ser formadas e dotadas de capacidade governante para constituírem, mediante procedimentos de abertura, cooptação, renovação e acomodação, as condições de "estrutura" (coesão social), segurança e liberdade necessárias para o regime democrático. ${ }^{14}$

Esse amplo entendimento, aliás, ainda seria colocado nos anos 1970 de acordo com a aguda concepção dos anos 1950 e 1960, de que a Guerra Fria (cf. Saunders, 1999), um acontecimento de "guerra total" ou psicológica, deveria ser combatida nos "corações e mentes" e vencida na dimensão profunda dos valores e da moralidade. Certas orientações, portanto, permaneceriam relevantes ao informarem internacionalmente os debates sobre a "transição democrática" e, no Brasil, aquelas sobre a "descompressão” política. Destaquemos três:

a) a "institucionalização" dos regimes continuaria a ser um esforço central na defesa contra a "subversão" de esquerda e, por isso mesmo, para projetar "autoritarismos" e "autocracias", sem rupturas, rumo ao Estado de Direito e à democracia representativa; 
“Transição política” e ditadura no Brasil: os anos 1970 e seus agendamentos políticos e intelectuais

b) o trabalho de formação de elites, em razão de fragilidades atribuídas às condições de cultura e de civilização das sociedades "não desenvolvidas", continuaria focado em estabelecer quadros preparados mais para fundar projetos e instituições e para difundir ideias do que para exercer e orientar funções estritamente executivas;

c) a instabilidade política, vista como tendo entre suas motivações as pressões provenientes de elites "alienadas" do poder e de segmentos mobilizados e marginalizados da população, seria tratada não somente com repressão, mas com uma aposta nas possibilidades de "reconciliação" que a arregimentação desses grupos produziria, significando, também, entre as várias possíveis frentes de intervenção, uma abordagem à construção de pensamento, quadros e liderança de esquerda.

As políticas de investimento da Fundação Ford nas ciências sociais do período buscaram muito de sua orientação em perspectivas como essas. Um de seus marcos foi a inauguração de uma agenda especializada de expansão do fomento à área no Brasil, em 1967. Os novos investimentos, como informara Peter D. Bell, assistente da Divisão de América Latina e Caribe da Fundação, em maio daquele ano, ao então diretor do escritório no Brasil, Stacey H. Widdicombe ${ }^{15}$ teriam por início o Iuperj, pretendendo alcançar daí as várias disciplinas e seus representantes no Rio de Janeiro: a Escola de Economia, Sociologia e Política da PUC-Rio; o Museu Nacional e o Instituto de Ciências Sociais da Faculdade de Filosofia da Universidade do Brasil (futura UFRJ); o Instituto de Direito Público e Ciências Políticas (IDPCP) $)^{16}$ e a Escola Brasileira de Administração Pública (Ebap) da Fundação Getulio Vargas (FGV), e o Centro de Estudos e Pesquisas no Ensino do Direito (Ceped) da Universidade da Guanabara (futura Uerj).

Desses investimentos, esperava-se melhor formação e organização da comunidade de profissionais de Sociologia, Ciência Política e de Antropologia, e que a face técnico-científica das áreas de Economia, Direito e Administração fosse desenvolvida por meio da aproximação às ciências sociais. O modelo dessa aproximação, segundo Peter D. Bell, já estaria indicado na proposta do Departamento de Ciência Política da Universidade Federal de Minas Gerais (UFMG), que a Fundação Ford ajudou a fundar com seus recursos ainda em 1967. ${ }^{17}$ Peter J. Reichard, quando substituiu, em 1973, o assessor de programas para as ciências sociais no Brasil, no cargo desde 1967, Frank Bonilla, verificou que a implantação da linha de fomento vinha seguindo o planejamento de expandir-se nacionalmente, tendo entre seus novos beneficiários 
os departamentos de Antropologia e de Sociologia da Universidade de Brasília (UnB), o departamento de Ciência Política da Universidade Federal do Rio Grande do Sul (UFRGS), o Programa Integrado de Mestrado em Economia e Sociologia da Universidade Federal de Pernambuco (Pimes/UFPE), e o Cebrap e a Fundação Carlos Chagas, de São Paulo. ${ }^{18}$

Essa modalidade de investimentos, em expansão e realizada mediante esforços mútuos com órgãos federais de fomento como a Capes, ajudava a estabelecer, não apenas na Ciência Política, a proposta de formar quadros intelectuais dedicados a diagnosticar, sob rubricas como "democratização", "descompressão", "distensão" e "transição", modalidades de ação política e de mudanças que, como artes de governo, fossem adequadas à pretendida refundação de um Estado de Direito.

Na concepção sobre tais artes de governo, prevaleceria a tendência que Maria Sylvia de Carvalho Franco identificou, em 1970, como a dominante, desde o pós-Segunda Guerra Mundial, na produção de ciências sociais no Brasil: na reflexão sobre a democracia, e em como alcançá-la, o enfoque residia menos no tema das liberdades e mais no combate às formas sistêmicas de "irracionalidade" da vida social e econômica, consideradas pressupostos democráticos. Era meta desse trabalho intelectual, assim, identificar as manifestações do que seria "não moderno", bem como suas potencialidades de transformação, no sentido da modernidade e de ideais ocidentais de civilização; consequentemente, buscar, na dimensão técnica e na dos comportamentos, aumentar o nível de eficácia das transformações materiais, da produção e da organização social, que corresponderiam a essas mudanças, típicas da racionalidade moderna (Moreira, 1970).

Segundo Maria Sylvia, essas metas estariam gerando, na passagem para os anos 1970, uma programação de pesquisas e publicações de perspectiva comparada internacional, orientada, principalmente, à investigação sobre os sistemas jurídico, político e de relações sociais. Com base nessa investigação seria possível aferir, ao mesmo tempo, os traços "não modernos" mais característicos do Brasil e os pontos ótimos de sua desarticulação. À diversidade de agendas políticas corresponderiam diferentes aspectos do "atraso" brasileiro, considerados aceitos e prioritários; mas, também, um ponto era unânime: a avaliação de que a "transição democrática", esse sentido de futuro, deveria ser uma tarefa de "racionalização", de planejamento político e de intervenção na vida social. Quanto à liberdade, ela não seria dotada de um princípio racional; seria uma "des-razão": dotada de atributos, novas possibilidades de ação, que 
apenas o pleno "desenvolvimento político" poderia começar a satisfazer sem arriscá-la à irracionalidade (Moreira, 1970). ${ }^{19}$

A análise de Maria Sylvia, assim, captava, já na época, a tendência de desenvolvimento, especialmente entre cientistas sociais dos anos 1970, de uma reflexão sobre como prosseguir na modernização promovida pela ditadura, deslegitimando o regime e possibilitando uma "transição" ordeira para a democracia, embora mediante uma renovação evolutiva das alianças de poder que constituíram o golpe de 1964 (Cancelli, 2017, p. 125). Assim, a reflexão sobre a "transição", que nascera no interior de um campo de estudos internacional e comparado, vinha sendo discutida em relação a certos princípios normativos guia: primeiramente, frente às novas estratégias globais de desenvolvimento econômico; em segundo lugar, tendo em vista a reforma do Estado, em termos da legalidade do Estado de Direito, da observância aos direitos humanos e da institucionalização de certas possibilidades de participação política. Tratava-se, portanto, de diagnósticos, a partir das ciências sociais, para a ação política.

As CIÊNCIAS SOCIAIS E A FORMAÇÃO DE UM AGENDAMENTO PELA “TRANSIÇÃO”

Na avalição de Fernando Henrique Cardoso, feita em 1971, expressava-se a posição do Cebrap, endossada em uma leitura da condição "dependente e associada" do Brasil. Para ele, o país era dotado de uma "burguesia internacionalizada" que abria espaços para o crescimento de uma burguesia com horizonte e atuação nacionais, acomodando as classes médias e integrando alguns segmentos populares. A condição geral da sociedade seria de estabilidade e de crescimento econômico; portanto, segundo Fernando Henrique, então propícia à abertura do regime de 1964 para uma "agenda democrática" nos anos 1970. Entretanto, ocorreria justamente o contrário. De certa maneira, contrariando o princípio, para ele, de que a observada modernização da sociedade brasileira, para ser continuada, deveria trazer consigo também o desenvolvimento político e a liberação da esfera pública.

O acirramento do foco repressivo, que a ditadura, na passagem daquela década, justificava no combate à esquerda armada, seria problemático também para o próprio regime, por várias razões. Para Fernando Henrique Cardoso, a ditadura estaria com essa investida alienando apoiadores e segmentos sociais importantes e, por isso, incorrendo no risco de gerar mais fechamento político 
sobre si, além de "paralisia social". A repressão privaria o processo de modernização de recursos humanos fundamentais, estratégicos, criando uma dinâmica de desagregação na qual vários distanciamentos poderiam estar se processando: um, entre elites culturais e intelectuais e elites políticas; outro, entre o conjunto dessas elites e as camadas populares. Esse efeito de desagregação, segundo o sociólogo, se não favorecia a estabilidade do regime, tampouco beneficiaria as oposições a ele (Cardoso, 1979, Prefácio e cap. 1, 3 e 9).

Cândido Mendes sustentou, entre essas leituras inaugurais dos anos 1970, uma avaliação próxima à de Fernando Henrique Cardoso, que ambos partilhavam com segmentos importantes das elites jurídicas do país. Todos eles tinham em vista que os Atos Institucionais (AIs) do regime, instrumentos de "compressão" política, executados para assegurar principalmente o cumprimento de uma agenda de modernização, estavam impedindo que se desse adequado tratamento às mudanças políticas e sociais, produzidas por essa mesma modernização (Cattai, 2018, cap. 5). Não sem motivo, assistiu-se, nos anos 1970, a um recorrente recurso da parte dos politólogos e de políticos brasileiros, de dentro e de fora do regime, às teses e aos conselhos de Samuel Huntington. Buscava-se nele principalmente uma programação clara sobre como dar andamento a uma "descompressão", à modernização da vida política e a uma "abertura" que fosse feita paulatina e crescentemente, sempre equilibrando e pressionando para que o exercício de "arbitrariedades" se coadunasse com o cumprimento de certos rigores institucionais (Cancelli, 2017).

A proposta de Fernando Henrique Cardoso era de que a saída dessa situação estava na construção de novas bases nacionais de consenso, mas alertava que seria impraticável, como base dessa conciliação de interesses, qualquer projeção "nacionalista”, de qualquer tradição. Segundo ele, aspirações desse tipo (da esquerda à direita), ainda dotadas de lastro material nos anos 1960, haviam sido refeitas pela ditadura. As "burguesias nacionais" encontravam-se confortáveis, pois cresceram no processo "dependente e associado" de internacionalização da economia brasileira. Perdido esse apelo em seus antigos arautos, ficava, para o sociólogo, aberta a questão sobre como deveria se constituir essa que se tomava como uma premente e nova unidade moral e ideológica nacional. Ainda assim, para ele, já se tornava, até certo ponto, possível vislumbrar ao menos três determinantes principais de onde as novas bases de consenso seriam retiradas ou de onde seriam pressionadas. Segundo Fernando Henrique: 
“Transição política” e ditadura no Brasil: os anos 1970 e seus agendamentos políticos e intelectuais

1) as áreas de ponta da produção (as empresas multinacionais), através especialmente da renovada pressão política de seus trabalhadores, impulsionariam a formação de um novo tipo de "unidade burguesa", e desta, com o trabalho;

2) as críticas de esquerda e direita dos anos 1960 à forma liberal da democracia representativa seriam revistas em favor do Estado de Direito e da retomada de direitos civis;

3) os Estados Unidos seriam preponderantes para as chances de consolidação de quaisquer saídas de "transição democrática". (Cardoso, 1979)

Nessa abertura dos anos 1970, toda uma intelectualidade passara a propor, a partir das ciências sociais, um novo dilema, para ela, pendente de solução: que artes de governo seriam as mais apropriadas para essas problemáticas, emergentes no país e no mundo, na passagem dos anos 1960 para os 1970 ? Notemos que a questão anterior - que personalidades relevantes como Hélio Jaguaribe e Cândido Mendes propuseram no período da grande agitação para o golpe de $1964^{20}$ - era como fazer a "decolagem" do subdesenvolvimento para a modernidade, projetando-se que soluções autoritárias temporárias mostravam-se como opções viáveis, na medida em que permitiriam proteger a modernização de certo potencial de ruptura no Brasil. Ou seja, graças àqueles que seriam os níveis caracteristicamente baixos de integração e de consenso social do país, gerados pelo isolamento das "massas" e da homogeneidade das "elites", haveria por parte dos "extremos" sociais uma potencial inclinação pelo "radicalismo" e pela "irracionalidade" (Jaguaribe, 1962, Livro 1, cap. 4; Almeida, 1963, cap. 9). Não sem razão, justificavam-se como um "mal menor" as medidas de "compressão política" pela modernização tão bem-acabadas nos Atos Institucionais.

Já nos anos 1970, as orientações de ambos, partilhadas no Iuperj, assim como do próprio Fernando Henrique Cardoso, em relação à modernização, formação e institucionalização de um consenso capaz de preservar a ordem contra rupturas, vieram alicerçadas em uma preocupação geral de Guerra Fria, quanto à atualização e rearranjo de alianças nacionais e internacionais. O novo dilema passara a se formular, assim, da seguinte forma: no caso da "transição" para o Brasil do futuro, frente a um mundo de mudanças técnicas radicais e a novos sentidos para o que significa uma boa governança, o que, em um vindouro rompimento com a ditadura, deveria ser protegido de ruptura? 


\section{CONSIDERAÇÕES FINAIS}

Tratava-se, portanto, naqueles anos 1970, da produção de todo um vocabulário político e conceitual que, se, por um lado, era conducente a um renovado esforço de acomodação ao poder norte-americano, por outro, fundamentava o desenvolvimento do enorme campo disciplinar das teorias e propostas de "transição" de regimes autoritários; campo que, segundo Gerard Munck (2011), estrutura a atual teoria democrática dominante no mundo na área de Ciência Política. Certa literatura, mais recente (Moyn, 2018, cap. 5), tem destacado que tal vocabulário estabeleceu algumas orientações centrais e que nos alcançam até hoje em nossas formas de organização política, entre elas: a caracterização estrita da democracia pelo conjunto de seus procedimentos legais e paralegais e, portanto, pela racionalização dos processos de institucionalização da vida política; a transformação (e despolitização potencial) da noção de direitos humanos, passando a ser associada a uma ideia mais limitada de satisfação das "necessidades básicas"; e o estabelecimento de um ideal de pluralidade democrática que passou a operar na condição de instrumento de gerenciamento da vida pública.

Do ponto de vista da pesquisa e da análise historiográfica, é mister interrogar os fundamentos desse trabalho de redimensionamento das liberdades que a "transitologia" legou ao nosso tempo presente sem incorrer em seus sintomas. Que se interrogue essa produção em sua orientação teórica ao buscar, na sua produção e em suas práticas políticas, uma fonte de pesquisa sobre a nossa atual imaginação política e sobre nossas formas de vida democrática; portanto, da nossa condição de liberdade e diversidade. No que diz respeito especificamente ao Brasil, as vertentes da "teoria da dependência" que se reestruturaram e se recompuseram no interior dos estudos sobre transição de regimes autoritários, nomeadamente como as teorias sobre o "Estado Burocrático-Autoritário”, parecem-nos um campo de partida profícuo, o qual merece, ainda, uma investigação.

\section{REFERÊNCIAS}

ALMEIDA, Cândido A. Mendes de. Nacionalismo e desenvolvimento. Rio de Janeiro: Instituto Brasileiro de Estudos Afro-asiáticos, 1963.

AMORIM, Felipe Colla de. Institucionalização da Ciência Política no Brasil: o Iuperj, a Fundação Ford e o debate sobre a transição. In: SEMINÁRIO DE ESTUDOS SOBRE A GUERRA FRIA, 2., 2018, São Paulo: Universidade de São Paulo. Mimeo. 
“Transição política” e ditadura no Brasil: os anos 1970 e seus agendamentos políticos e intelectuais

BRZEZINSKI, Zbigniew. Entre duas eras: América Laboratório do Mundo. Tradução: J. A. Fortes. Rio de Janeiro: Artenova, 1971.

CANCELLI, Elizabeth. O Brasil em Guerra Fria Cultural: o pós-guerra em releitura. São Paulo: Iluminuras, 2017.

CARDOSO, Fernando Henrique. O modelo político brasileiro. [1971]. 4. ed. São Paulo: Difel, 1979.

CATTAI, Júlio B. Pignata. A revolta dos fatos contra a lei: antitotalitarismo e modernização jurídica no Brasil da Guerra Fria. 2018. Tese (Doutorado em História Social) - Departamento de História, FFLCH, Universidade de São Paulo (USP). São Paulo, 2018.

CHAVES, Wanderson. A questão negra: a Fundação Ford e a Guerra Fria (1950-1970). Curitiba: Prismas, 2018.

DEZALAY, Yves; GARTH, Bryant G. The Internationalization of Palace Wars: Lawyers, Economists, and the Contest to Transform Latin American States. Chicago: The University of Chicago Press, 2002.

EHRMAN, John. Liberals, Neoconservatives, and Foreign Policy: 1945-1985. Tese (Doutorado) - Columbian College and Graduate School of Arts and Sciences, The George Washington University. Washington, DC, 1993.

FORJAZ, Maria Cecília S. A emergência da Ciência Política no Brasil: aspectos institucionais. Revista Brasileira de Ciências Sociais, São Paulo: Anpocs, v. 12, n. 35, 1997.

GILMAN, Nils. Mandarins of the Future: Modernization Theory in Cold War America. Baltimore: The Johns Hopkins University Press, 2003.

GREEN, James N. Apesar de vocês: oposição à ditadura brasileira nos Estados Unidos, 1964-1985. Tradução: S. Duarte. São Paulo: Companhia das Letras, 2009.

GUILHOT, Nicolas. The Democracy Makers: Human Rights and the Politics of Global Order. New York: Columbia University Press, 2005.

GUILHOT, Nicolas (ed.). The Invention of International Relations Theory: Realism, the Rockefeller Foundation, and the 1954 Conference on Theory. New York: Columbia University Press, 2011.

HOEVELER, Rejane C. Ditadura e democracia restrita: a elaboração do projeto de descompressão controlada no Brasil (1972-1973). 2012. Monografia (Bacharelado em História) - DH, Universidade Federal do Rio de Janeiro (UFRJ). Rio de Janeiro, 2012.

HOEVELER, Rejane C. As elites orgânicas transnacionais diante da crise: os primórdios da Comissão Trilateral (1973-1979). 2015. Dissertação (Mestrado em História) Universidade Federal Fluminense (UFF). Niterói, 2015.

HUNTINGTON, Samuel P. Political Order in Changing Societies. New Haven, CN: Yale University Press, 1968. 
IORIS, Rafael R. Qual desenvolvimento: os debates, sentidos e lições da Era Desenvolvimentista. Jundiaí, SP: Paco, 2017.

JAGUARIBE, Hélio. Desenvolvimento econômico e desenvolvimento político. Rio de Janeiro: Fundo de Cultura, 1962.

KOREY, William. Taking on the World's Repressive Regimes: The Ford Foundation's International Human Rights Policies and Practices. New York: Palgrave Macmillam, 2007.

LEMOS, Renato Luís do C. N. e. A conexão Harvard e a política de descompressão: sobre as origens da transição política no Brasil pós-1964. Revista Tempos Históricos, Marechal Cândido Rondon, PR: Unioeste, v. 18, n. 2, 2014.

LOUREIRO, Felipe P. Empresários, trabalhadores e grupos de interesse: a política econômica dos governos Jânio Quadros e João Goulart, 1961-1964. São Paulo: Ed. Unesp, 2017.

MELLO, Natália N. de. Do desenvolvimento global ao paradigma da ordem e da estabilidade: representações dos países pobres na teoria do desenvolvimento político norte-americana. 2009. Dissertação (Mestrado em Ciência Política) - FFLCH, Universidade de São Paulo (USP). São Paulo, 2009.

MICELI, Sérgio. A desilusão americana. Brasília: CNPq; São Paulo: Idesp: Sumaré, 1990.

MOREIRA, Maria Sylvia de C. Franco. O moderno e suas diferenças. 1970. Tese (Livre-docência) - FFLCH, Universidade de São Paulo (USP). São Paulo, 1970.

MOYN, Samuel. Not Enough Human Rights in an Unequal World. Cambridge, MA: The Belknap Press of Harvard University Press, 2018.

MUNCK, Gerardo L. Democratic Theory After Transitions from Authoritarian Rule. In: APSA, 2011, Annual Convention. Prepared for delivery at the 2011 American Political Science Association (APSA). Seattle, Sep. 1-4, 2011.

PARMAR, Inderjeet. Foundations of the American Century: The Ford, Carnegie, and Rockefeller Foundations in The Rise of American Power. New York: Columbia University Press, 2012.

PEREIRA, João Márcio M. O Banco Mundial como ator político, intelectual e financeiro (1944-2008). 2009. Tese (Doutorado em História) - PPGH, Universidade Federal Fluminense (UFF). Niterói, 2009.

SABELLA, Jeremy Luis. The Politics of Original Sin: Reinhold Niebuhr's Christian Realism and Its Cold War Reception. 2013. Dissertation (Doctor of Philosophy) - Department of Theology, The Graduate School of Arts and Sciences, Boston College. Boston, 2013.

SELZNICK, Philip. Leadership in Administration: A Sociological Interpretation. Evanston, IL: Row, Peterson, 1957.

SELZNICK, Philip. The Organizational Weapon: A Study of Bolshevik Strategy and Tatics. New York: McGraw-Hill, 1952. 
“Transição política" e ditadura no Brasil: os anos 1970 e seus agendamentos políticos e intelectuais

\section{NOTAS}

${ }^{1}$ Essa programação foi de grande importância no desenho de uma ampla estratégia de agendamento político norte-americana de Guerra Fria estabelecida nos anos 1950 e 1960, particularmente (cf. CANCELLI, 2017; CHAVES, 2018; CATTAI, 2018) no que diz respeito às implicações globais dessa programação no Brasil.

${ }^{2}$ O livro Leadership in Administration (SELZNICK, 1957), lançado em português em 1971 pela Fundação Getulio Vargas, foi especialmente influente nessa concepção sobre qual haveria de ser o sentido de liderança do trabalho intelectual.

${ }^{3}$ Essa argumentação, presente em trabalhos comissionados pela Rand Corporation (SELZNICK, 1952), articulava a promoção de uma autonomia das elites a táticas de defesa e combate à "subversão".

${ }^{4}$ Memorando de Peter S. Cleaves para Eduardo L. Venezian, de 30 de março de 1976. In: Rockefeller Archive Center. Ford Foundation Records. Grant Files. Reel no. 5490.

${ }^{5}$ O Instituto de Estudios Peruanos foi fundado em 1964; o Iuperj, entre 1966 e 1967; o Cebrap, em 1969; e o Cedes, em 1975.

${ }^{6}$ Ver o memorando de James Gardner [assessor de programas da Divisão de América Latina e Caribe] para William Carmichael [chefe da Divisão], de 15 de maio de 1972; o de Richard Morse [assessor de programas do escritório no Brasil] para Eduardo L. Venezian [diretor do escritório], de 25 de julho de 1975; e o de Shepard Forman [assessor de programas do escritório no Brasil] para James Gardner [diretor do escritório], de 24 de maio de 1979. In: Rockefeller Archive Center. Ford Foundation Records. Grant Files. Reel no. 5351.

${ }^{7}$ Foi constituída, em 1966, uma equipe de consultores para reportar a atuação do Iuperj à Fundação Ford e fazer recomendações. Participaram, além de Huntington, Luís Navarro de Brito, chefe do Gabinete Civil da Presidência da República (1966-1967), futuro secretário da Educação e Cultura do Estado da Bahia (1967-1971); o padre Fernando Bastos Ávila, vice-reitor e diretor da Escola de Sociologia, Política e Economia da Pontifícia Universidade Católica do Rio de Janeiro (PUC-Rio); o cientista político Ronald Schneider, da Columbia University; e o cientista político Alex Inkeles, da Harvard University. Cf. carta de Cândido Mendes para Stacey Widdicombe [diretor do escritório da Fundação Ford no Brasil]. Rio de Janeiro, 8 de dezembro de 1966. In: Rockefeller Archive Center. Ford Foundation Records. Grant Files. Reel no. 5351.

${ }^{8}$ Referimo-nos (cf.: CANCELLI, 2017, cap. 3) à posição especial, mas não exclusiva de "liberais de centro", de que a aceleração do desenvolvimento econômico responderia à ameaça das propostas comunistas, ao conferir estrutura para uma agenda de reformas sociais. Segundo essa aposta, haveria evolutiva modernização social e democratização política atravessando a transformação capitalista, processo que amadureceria e tornaria mais complexa e estável a ordem econômica das sociedades "subdesenvolvidas".

${ }^{9}$ A literatura mais atual (IORIS, 2017; LOUREIRO, 2017) corrobora essa verificação de 
que o Brasil experimentou uma dinâmica de intenso crescimento e transformação econômicos nas primeiras décadas do pós-guerra.

${ }^{10}$ A CIA, em um de seus "sumários semanais" de janeiro de 1967, na apresentação de um perfil do novo presidente do Brasil, Artur da Costa e Silva, indicava que estudantes, intelectuais e a esquerda comunista vinculada às organizações de trabalhadores eram os grandes desafios da nova administração. Cf.: DIRECTORATE OF INTELLIGENCE. Central Intelligence Agency. Weekly Summary - Special Report. Costa e Silva, Brazil's Next President. Secret - no. 45. 20 january 1967 (no. 0273/67A).

${ }^{11}$ Huntington (cf.: LEMOS, 2014; HOEVELER, 2012) estava familiarizado com essa problemática brasileira. Passou a visitar o país com certa frequência a partir de 1965, geralmente com a assistência de Cândido Mendes de Almeida, participando de eventos acadêmicos e de debates políticos, tornando-se, desde então, crescentemente influente entre cientistas sociais brasileiros, especialmente entre cientistas políticos. Em 1968, Huntington tornou-se consultor do Departamento de Estado Norte-Americano e também passou a oferecer, como já fazia em outros países, consultoria ao governo brasileiro.

${ }^{12}$ A tradução brasileira, A ordem política nas sociedades em mudança, foi publicada em 1975 e teve a revisão técnica de Renato Raul Boschi, então professor do Iuperj.

${ }^{13}$ A Comissão Trilateral foi criada em 1973 por Brzezinski e pelo magnata David Rockefeller. A Comissão partia, justamente, do entendimento de que haveria uma profunda "crise da democracia", de legitimidade e de autoridade dos governos, o que teria tido culminância com os protestos e rebeliões de 1968-1969, nos Estados Unidos e na Europa, e que se nutririam do radicalismo anti-establishment da New Left (DEZALAY; GARTH, 2002; HOEVELER, 2015).

${ }^{14} \mathrm{O}$ teólogo cristão Reinhold Niebuhr, intelectual público muito atuante entre os anos 1930 e 1960 e influente entre diferentes vertentes ideológicas da política externa dos Estados Unidos - seu pensamento chegou a ser recuperado recentemente pela administração de Barack Obama -, produziu (cf.: SABELLA, 2013) uma obra fronteiriça entre a filosofia moral e a filosofia política que ajudou, até certo ponto, a inspirar a construção dessas orientações convergentes.

${ }^{15}$ Memorando de Peter D. Bell para Stacey H. Widdicombe, de 2 de maio de 1967. In: Rockefeller Archive Center. Ford Foundation Records. Grant Files. Reel no. 5351.

${ }^{16}$ A partir de 1973, passou a se chamar Indipo.

${ }^{17}$ Memorando de Peter D. Bell para Stacey H. Widdicombe, de 2 de maio de 1967, cit. A literatura especializada (FORJAZ, 1997; MICELI, 1990), em avaliações de longo prazo, ratifica como exitoso o planejamento de Bell, confirmando a especialidade do Departamento de Ciência Política da UFMG na institucionalização da disciplina e na proposta de aproximação da Economia e do Direito.

${ }^{18}$ Carta de Peter J. Reichard para Stanley Nicholson [diretor do escritório no Brasil] e para Richard Morse, de 20 de junho de 1973. In: Rockefeller Archive Center. Ford Foundation Records. Grant Files. Reel no. 5490. 
${ }^{19}$ A análise da autora parte de uma exegese dos usos de Max Weber pelas ciências sociais no Brasil do pós-Segunda Guerra Mundial, centrada nas apropriações da Sociologia norte-americana, especialmente as feitas por Talcott Parsons e Seymour Martin Lipset. Segundo Maria Sylvia, essas apropriações brasileiras deram livre curso a dois fundamentos dessa Sociologia. Em primeiro lugar, e contra uma posição sustentada pelo próprio Weber, à negação do preceito kantiano de que a liberdade goza do princípio de racionalidade. Portanto, contra a ideia de que ela, a liberdade, é um querer conforme a razão. Em segundo lugar, à investigação das transições do "primitivo" para o "moderno". Em termos epistemológicos, esse fundamento seria original da Etnologia do século XIX de autores como Lewis Morgan. Isto é, da investigação sobre como a modernidade do ideal de progresso poderia nascer das diferentes maneiras como sistemas de parentesco reconhecem e regulamentam a propriedade.

${ }^{20}$ Respectivamente, em Desenvolvimento econômico e desenvolvimento político (JAGUARIBE, 1962) e em Nacionalismo e desenvolvimento (ALMEIDA, 1963). 